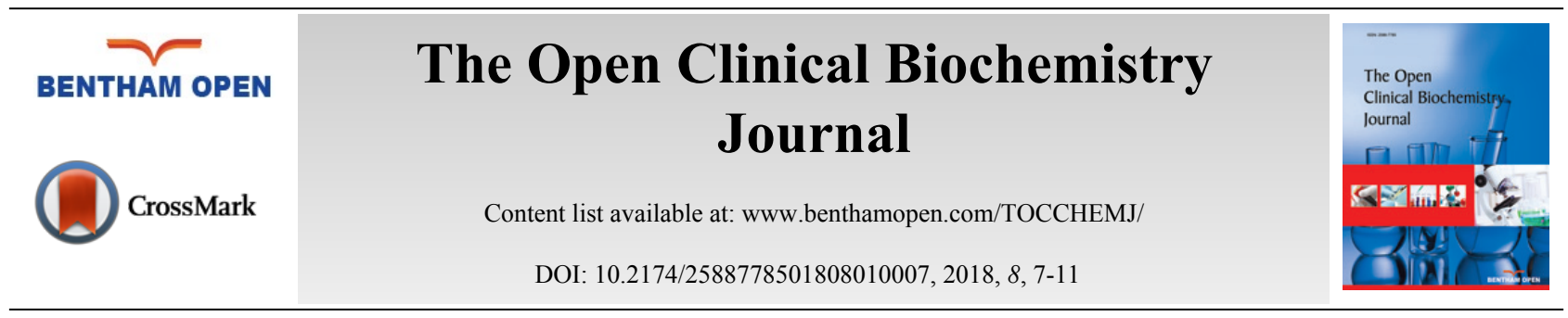

RESEARCH ARTICLE

\title{
Estimation of Prolactin and HbA1c among Type 2 Diabetic Male with Retinopathy in Khartoum State
}

\author{
Malaz Salah Abdallah ${ }^{1}$, Nesrin Abdalla Ahmed ${ }^{2}$ and Abdel karim A. Abdrabo, \\ ${ }^{I}$ Department of Clinical Chemistry, Faculty of Medical Laboratory Science, Al-Neelain University, Khartoum, Sudan \\ ${ }^{2}$ Ophthalmologist, Makkah Hospital, Khartoum, Sudan
}

Received: July 24, 2018

Revised: October 23, 2018

Accepted: October 28, 2018

\begin{abstract}
:
Background:

Diabetic Retinopathy (DR) is one of the long-term complications of Diabetes Mellitus (DM) and constitutes the leading cause of blindness in working-age individuals. Prolactin (PRL) is a peptide hormone that is linked with lactation but many studies have demonstrated that PRL could have protective value against DR.
\end{abstract}

Aim:

To evaluate the role of prolactin in pathophysiology of DR.

Methods:

This study is designed to find an association between PRL level and DR. In this case-control study, a total of 300 subjects were recruited to participate in the study, 150 subjects apparently healthy as control group and other 150 patients were diagnosed with type 2 DM who were classified into diabetic patients with DR (75) and diabetic patients without DR (75). Serum PRL was measured by autoanalyzer (TOSOH AIA system), HbAlc was measured by another automated chemical analyzer (Cobas c system). Statistical analysis was performed using SPSS version 21 using an independent samples T-test and Pearson's correlation.

Results:

Independent samples of T-test analysis show a significant decrease in PRL level in the diabetic patients with DR in comparison to the diabetic patients without DR $(p<0.05)$. Person's correlation revealed that there was an insignificant correlation between PRL level with duration of DM and patients age.

\section{Conclusion:}

These findings suggest that low PRL level might be associated with DR.

Keywords: Diabetic Retinopathy, Prolactin, Vasoinhibin, Sudanese, VEGF, Matrix Metalloproteases.

\section{INTRODUCTION}

Diabetic Retinopathy (DR) is one of the long-term complications of diabetes that develops from microangiopathy. DR is initiated by loss of pericyte and endothelial cells of the retinal capillary that lead to the increased retinal vasopermability, causing exudates, intraretinal hemorrhages and capillary closure which cause hypoxia. Vascular Endothelial Cell Growth Factor (VEGF) is locally produced as a result of hypoxia. VEGF stimulates microangiogenesis and the newly formed blood vessels extended to vitreous causing vitreous bleeding, fibrosis and

* Address correspondence to this author at the Department of Clinical chemistry, Faculty of Medical Laboratory Science, Al-Neelain University, Khartoum, Sudan; Tel: +249912905847; E-mail: abdrabokarim@hotmail.com 
at last stage retinal detachment and loss of vision [1]. PRL, the hormone produced by anterior pituitary gland is essential for lactation, apart from this classical function PRL has many actions in reproduction regulation, osmoregulation, brain function and behavior, immune response, energy metabolism and angiogenesis [2, 3]. Among these actions, energy metabolism and regulation of angiogenesis could be protective against DR. Moreover, many experimental studies have documented that PRL level plays a role in the regulation of blood glucose and acts on pancreatic $\beta$ cells to stimulate proliferation, survival, synthesis and secretion of insulin as documented by Brelje TC et al. [4]. As documented by Holstad M and Sandler S [5], by increasing islet number and reducing mononuclear cell infiltration, PRL is able to protect against the development of hyperglycemia in diabetic rats. Also, PRL has an important mechanism to delay the progressions of DM and DR by proteolytic conversion to vasoinhibin, PRL is cleaved by cathepsin D, Matrix Metalloproteases (MMP), and bone morphogenetic protein-1 to yield vasoinhibins [2]. Vasoinhibins are potent inhibitors of blood vessels in the eye, also there are many experimental studies that have evaluated the role of vasoinhibin for anti-microangiogensis. The local administration of vasoinhibins reduces the stimulation of corneal angiogenesis induced by Basic Fibroblast Growth Factor (bFGF) [6]. Gene transfer of vasoinhibins via an adenoviral vector inhibits ischemia-induced retinal angiogenesis [7]. Furthermore, vasoinhibins block increased retinal vasopermeability in diabetic rats and in response to intravitreous injection of Vascular Endothelial Cell Growth Factor (VEGF) or of vitreous from patients with DR [8]. Other than experimental studies, there are many reports showing association between PRL level and DR, the circulating levels of PRL was increased in diabetes and were higher in diabetic patients without DR than in those with proliferative DR. Edith Arnold et al., 2010 [9], and Jakob Triebel et al., 2009 [10] documented that the group with DR had significantly lower PRL-V (vasoinhibin) serum concentrations than the control group.

\section{MATERIALS AND METHODS}

This descriptive analytical case-control study was carried out in Khartoum state from April 2017 to August 2017 at the Mecca Eye Complex. The sample size was calculated on the basis of a review article by Charan J and Biswas T. [11] using the formula for case-control studies, quantitative variables. Three hundred subjects were included in this study, classified as 150 healthy males or control and 150 type 2 diabetic male as cases. The case group included diabetic patients with DR (75) and diabetic patients without DR (75). The diabetic group was diagnosed according to the WHO's criteria [12,13], patients with prolactinoma, chronic kidney disease, thyroid disorders, liver disease and female subject were excluded from the study. The study had been approved by the local ethics committee of Al-Neelain University. Data was collected using a structural interviewing questionnaire, which was designed to collect and maintain all valuable information concerning each case examined. A $5.0 \mathrm{ml}$ of venous blood was collected by safe aseptic procedures. For HbA1c, $2.5 \mathrm{ml}$ of blood was collected in EDTA anticoagulant container and stored at $6^{\circ} \mathrm{C}$ until the analysis; for prolactin $2.5 \mathrm{ml}$ of blood was placed in plain containers; blood was allowed to clot at room temperature, then the sample was centrifuged for $3 \mathrm{~min}$ at $4000 \mathrm{rpm}$ and the serum separated. Serum samples were stored below $-20^{\circ} \mathrm{C}$. At the time of analysis, samples were thawed and mixed before assay.

\subsection{Laboratory Analysis}

Serum PRL was measured by automated Immunoassay analyzer AIA (TOSOH) system, HbA1c was measured by a fully automated chemical analyzer Cobas c 3011 system.

\subsection{Statistical Analysis}

Statistical analysis was performed using Software Statistical Package for Social Sciences (SPSS) version 21. The result is expressed as mean, SD and percentage. Quantitative results were analyzed statistically using independent samples T-test and One-Way ANOVA test for comparison between groups, Pearson's correlation was used to correlate between the study parameter and study variables. p-value less than 0.05 was considered as statistically significant at $95 \%$ confidence interval.

\section{RESULTS}

All subjects were age-matched and ranged between 38 to 77 years old. Samples were analyzed to measure the PRL level and $\mathrm{HbAlc}$, and results were analyzed statistically and data were represented as mean SD and percentage. Table 1 shows a descriptive summary of the study variables and HbA1c within the case group. Table $\mathbf{2}$ shows a comparison between Age, HbA1c and PRL level among the case and control group, there is a highly significant increase in the mean level of PRL in case group in comparison to control (p-value 0.02) where the mean level of PRL is $9.21 \pm 6.46$ in 
the case group and $8.28 \pm 2.32$ in control. One-Way ANOVA analysis showed a significant difference between the three groups (Control, patients with DR and patients without DR), P.value 0.002. Table 3 shows a comparison between age, HbA1c, duration and PRL level among diabetic patients with DR and diabetic patients without DR. Within the case group, there is a significant decrease in the level of PRL in DR patients in comparison to diabetic patients without DR (p-value 0.007), where the mean level of PRL is $8.41 \pm 2.29$ for DR patients and $10.12 \pm 1.24$ for diabetic patients without DR. Table 4 shows the correlation between PRL levels and study variables within the case group, there is no correlation observed between PRL levels and patients age $(R=-0.022, p=0.985)$, also no correlation between PRL levels and duration of diabetes $(\mathrm{R}=0.044, \mathrm{p}=0.666)$. The correlation analysis also indicated no correlation between PRL levels and HbA1c\% $(\mathrm{R}=-0.169, \mathrm{p}=0.092)$. Table 5 shows a comparison between PRL level and type of treatment within the case group, there is a significant increase in the mean level of PRL in patients that were treated with tablets in comparison to those treated with insulin (p-value 0.008), where the mean level of PRL is 12.20 for tablet user and 11.16 in insulin-treated patients.

Table 1. Descriptive summary of the study variables and HbA1c (\%) within the case group.

\begin{tabular}{|c|c|c|c|}
\hline Variables & Minimum & Maximum & Mean \pm SD \\
\hline Age (Years) & 38.00 & 77.00 & $61.25 \pm 8.45$ \\
\hline Duration (Years) & 1.00 & 40.00 & $15.10 \pm 8.51$ \\
\hline Hb A1c (\%) & 6.20 & 16.90 & $10.32 \pm 2.12$ \\
\hline
\end{tabular}

Table 2. Shows a comparison between Age, HbA1c and prolactin level among the case and control group.

\begin{tabular}{|c|c|c|c|}
\hline Parameters & Case (Mean \pm SD) & Control (Mean \pm SD) \\
\hline Age (years) & $61.25 \pm 8.44$ & $62.96 \pm 8.59$ \\
\hline Prolactin (ng/ml) & $9.21 \pm 6.46$ & $8.28 \pm 2.32$ & 0.247 \\
\hline Hb Alc (\%) & $10.32 \pm 2.21$ & 5.0 & $<0.020$ \\
\hline
\end{tabular}

Table 3. Shows a comparison between Age, HbA1c, Duration and Prolactin level among the DR and NDR (without DR) patients within the case group.

\begin{tabular}{|c|c|c|c|}
\hline Parameters & Patients with DR (Mean \pm SD) & Patients without DR (Mean \pm SD) \\
\hline Age (years) & $61.57 \pm 8.05$ & $60.61 \pm 9.25$ & 0.247 \\
\hline Duration (years) & $16.63 \pm 8.45$ & 0.011 \\
\hline Prolactin (ng/ml) & $8.41 \pm 2.29$ & $10.12 \pm 1.24$ & 0.007 \\
\hline HbA1c (\%) & $10.16 \pm 2.10$ & $0.62 \pm 2.13$ \\
\hline
\end{tabular}

Table 4. Shows the correlation between PRL level and study variables within the case group.

\begin{tabular}{|c|c|c|}
\hline Correlation & R-value & P-value \\
\hline PRL-Age & -0.002 & 0.985 \\
\hline PRL -Duration & 0.044 & 0.666 \\
\hline PRL-HbA1c & -0.169 & 0.092 \\
\hline
\end{tabular}

Table. 5. Shows Comparison between prolactin level and types of treatment among the case group

\begin{tabular}{|c|c|c|}
\hline Groups & Frequency (\%) & Mean \pm SD \\
\hline Tablets & $54(54 \%)$ & $12.20 \pm 8.9$ \\
\hline Insulin & $42(42 \%)$ & $11.16 \pm 7.6$ \\
\hline p-value & \multicolumn{2}{|c|}{0.008} \\
\hline
\end{tabular}

\section{DISCUSSION}

The present study agrees with the study done by Edith Arnold et al., 2010 [9], who reported that the PRL level significantly increased in diabetes in comparison to control group and were higher in patients without DR than in those with proliferative DR. 
The present study also agrees with Jakob Triebel et al., 2009 [10], who developed a new technique to measure PRL$\mathrm{V}$ levels in the serum samples of DR patients and compared it with a group of healthy males and reported that the case group (patients with DR) had significantly lower PRL-V (which is a product of PRL after proteolysis) serum concentrations than the control group. This finding supports that there is an inverse correlation between the serum PRL level and DR, the inverse correlation suggests that circulated level of PRL can influence the DR progression by inhibition of vasopermeability and angiogenesis through PRL conversion to vasoinhibin. Studies of PRL and vasoinhibins in animal models by Brelje TC et al., 1993 [4], Holstad M et al., 1999 [5], Pan H et al., 2004 [7], García C et al., 2008 [8], and Triebel J et al., 2017 [14] discussed the effects of PRL and vasoinhibins; these authors reported that they may have an effect on DR and suggest these hormones as important targets for therapeutic interventions.

The finding of the present study supports the previous findings which revealed that the patients with DR have lower levels of PRL in circulating blood compared with healthy subjects. These findings indicate an inverse relationship between systemic PRL and development of DR. The inverse correlation between PRL and DR can be due to the fact that systemic PRL, after its conversion to vasoinhibins, influences the progression of DR. So diabetic patients with lower levels of PRL are at risk to develop DR. This suggestion can be supported by a previous finding, which reported that patients with DR have lower levels of circulating vasoinhibins than nondiabetic patients [9].

In view of the fact that PRL has antiangiogenic properties and a preventive effect on retinal vasopermeability, the findings disagree with Shokoofeh B et al., 2012 [15] who measured the PRL by (Immunotech, Beckman Intraassay $2.8 \%$ ) and not found any significant difference in PRL level between case (Diabetic patients with DR) and control group (Diabetic patients without DR), also they find a higher and significant differences in the duration of diabetes in patient suffering from DR than those without DR. The finding of the present study also disagrees with AbdelMoneim M et al., 2015 [15, 16], who measured PRL using specific ELISA kit (cat\#DS-EIA-Prolactin, DSI S.r.1., Saronno, Volonterio, Italy) and find non-significant differences in plasma PRL levels between diabetic patients with and without DR and also between the two diabetic groups $v s$. healthy controls, duration of diabetes was more than 10 years in patients with DR. The exclusion of the female from the study was to prevent the collection of incorrect information about the physiological situation such as pregnancy or lactation and any others factors usually kept hidden in our population that may affect the PRL results in the female, otherwise, the finding of the present study can represent both male and female.

\section{CONCLUSION}

The study concludes that low PRL level may be associated with DR in Sudanese population. Further study is needed to estimate the vasoinhibin level in Sudanese, also clinical trial is needed to evaluate the use of vasoinhibin as a preventive therapy against DR.

\section{ETHICS APPROVAL AND CONSENT TO PARTICIPATE}

The study had been approved by the local ethics committee of Al-Neelain University.

\section{HUMAN AND ANIMAL RIGHTS}

No Animals were used in this research. All human research procedures followed were in accordance with the ethical standards of the committee responsible for human experimentation (institutional and national), and with the Helsinki Declaration of 1975, as revised in 2013.

\section{CONSENT FOR PUBLICATION}

We obtained the written informed consent from each subject or subject's parent.

\section{CONFLICT OF INTEREST}

The authors declare no conflict of interest, financial or otherwise.

\section{ACKNOWLEDGEMENTS}

Declared none. 


\section{REFERENCES}

[1] Caldwell RB, Bartoli M, Behzadian MA, et al. Vascular endothelial growth factor and diabetic retinopathy: Pathophysiological mechanisms and treatment perspectives. Diabetes Metab Res Rev 2003; 19(6): 442-55. [http://dx.doi.org/10.1002/dmrr.415] [PMID: 14648803]

[2] Clapp C, Thebault S, Jeziorski MC, Martínez De La Escalera G. Peptide hormone regulation of angiogenesis. Physiol Rev 2009; 89(4): 1177-215. [http://dx.doi.org/10.1152/physrev.00024.2009] [PMID: 19789380]

[3] Freeman ME, Kanyicska B, Lerant A, Nagy G. Prolactin: Structure, function, and regulation of secretion. Physiol Rev 2000; 80(4): 1523-631. [http://dx.doi.org/10.1152/physrev.2000.80.4.1523] [PMID: 11015620]

[4] Brelje TC, Scharp DW, Lacy PE, et al. Effect of homologous placental lactogens, prolactins, and growth hormones on islet B-cell division and insulin secretion in rat, mouse, and human islets: Implication for placental lactogen regulation of islet function during pregnancy. Endocrinology 1993; 132(2): 879-87.

[http://dx.doi.org/10.1210/endo.132.2.8425500] [PMID: 8425500]

[5] Holstad M, Sandler S. Prolactin protects against diabetes induced by multiple low doses of streptozotocin in mice. J Endocrinol 1999; 163(2): 229-34. [http://dx.doi.org/10.1677/joe.0.1630229] [PMID: 10556772]

[6] Triebel J, Macotela Y, de la Escalera GM, Clapp C. Prolactin and vasoinhibins: Endogenous players in diabetic retinopathy. IUBMB Life 2011; 63(10): 806-10. [http://dx.doi.org/10.1002/iub.518] [PMID: 21913303]

[7] Pan H, Nguyen NQ, Yoshida H, et al. Molecular targeting of antiangiogenic factor 16K hPRL inhibits oxygen-induced retinopathy in mice. Invest Ophthalmol Vis Sci 2004; 45(7): 2413-9. [http://dx.doi.org/10.1167/iovs.03-1001] [PMID: 15223825]

[8] García C, Aranda J, Arnold E, et al. Vasoinhibins prevent retinal vasopermeability associated with diabetic retinopathy in rats via protein phosphatase 2A-dependent eNOS inactivation. J Clin Invest 2008; 118(6): 2291-300. [PMID: 18497878]

[9] Arnold E, Rivera JC, Thebault S, et al. High levels of serum prolactin protect against diabetic retinopathy by increasing ocular vasoinhibins. Diabetes 2010; 59(12): 3192-7.

[http://dx.doi.org/10.2337/db10-0873] [PMID: 20823101]

[10] Triebel J, Huefner M, Ramadori G. Investigation of prolactin-related vasoinhibin in sera from patients with diabetic retinopathy. Eur J Endocrinol 2009; 161(2): 345-53. [http://dx.doi.org/10.1530/EJE-09-0130] [PMID: 19477896]

[11] Charan J, Biswas T. How to calculate sample size for different study designs in medical research? Indian J Psychol Med 2013; 35(2): 121-6. [http://dx.doi.org/10.4103/0253-7176.116232] [PMID: 24049221]

[12] Melchionda N, Forlani G, Marchesini G, Baraldi L, Natale S. WHO and ADA criteria for the diagnosis of diabetes mellitus in relation to body mass index. Insulin sensitivity and secretion in resulting subcategories of glucose tolerance. Int J Obes Relat Metab Disord 2002; 26(1): 90-6. [http://dx.doi.org/10.1038/sj.ijo.0801847] [PMID: 11791152]

[13] Genuth S, Alberti KG, Bennett P, et al. Follow-up report on the diagnosis of diabetes mellitus. Diabetes Care 2003; $26(11)$ : $3160-7$. [http://dx.doi.org/10.2337/diacare.26.11.3160] [PMID: 14578255]

[14] Triebel J, Clapp C, Martínez de la Escalera G, Bertsch T. Commentary: Prolactin alters blood pressure by modulating the activity of endothelial nitric oxide synthase. Front Endocrinol (Lausanne) 2017; 8: 105. [http://dx.doi.org/10.3389/fendo.2017.00105] [PMID: 28588552]

[15] Shokoofeh B, Nasser S, Abrishami M, Haleh R. Serum prolactin level and diabetic retinopathy in type 2 diabetes prolactin and diabetic retinopathy. J Diabetes Metab 2012; 3(1): 1-3. [http://dx.doi.org/10.4172/2155-6156.1000173]

[16] Abdel Moneim M, Abd-Eltawab A, Mostafa-Aedeab G, Zaki KA, Ibrahim AM, Mohamed AA. Plasma prolactin level in type 2 diabetic patients with and without retinopathy. Aljouf University Medical Journal 2015; 2(3): 1-6.

(C) Abdalla et al.

This is an open access article distributed under the terms of the Creative Commons Attribution 4.0 International Public License (CC-BY 4.0), a copy of which is available at: https://creativecommons.org/licenses/by/4.0/legalcode. This license permits unrestricted use, distribution, and reproduction in any medium, provided the original author and source are credited. 